\title{
La inmigración extranjera en Chile a revisión: también proletarios, aventureros, desertores y deudores
}

Gilberto Harris Bucher

Universidad de Playa Ancha, Valparaíso. Chile

Este trabajo, apoyado en una sobretasa de información archivística inédita, se ocupa del estudio de "la otra inmigración", hasta ahora invisible, compuesta por los proletarios, aventureros, desertores y deudores. En rigor, los datos colacionados dan por tierra con la creencia, repetida por inercia, de que todos los extranjeros que se radicaron en Chile mudaron rápidamente de condición. Asimismo se rectifican lugares comunes, generalizaciones y errores de bulto que abundan en la literatura de "divulgación".

\section{Introducción}

Sería una irreverencia histórica mayúscula negar la importancia del elemento alógeno en el desenvolvimiento decimonónico chileno, aporte que ha sido sintetizado, en un penetrante ensayo, como "extraordinario en el pequeño comercio, la importación y la exportación, la creación de talleres e industrias, la introducción de nuevas técnicas, la prestación de servicios artesanales y profesionales y el manejo de las grandes casas comerciales y bancarias". ${ }^{1}$ En verdad, la trascendencia, en términos cualitativos, de la inmigración extranjera es algo que nadie puede discutir; mas, la afirmación de que los europeos en Chile "no se cuentan, se pesan", ${ }^{2}$ es una burda exageración. Pero más preocupante es que mucha información documental sea desechada a la hora de hacer apología, y que otros, que son los más, aún no se den a la tarea de compulsar la frondosa información archivística que guardan nuestros repositorios.

Las notas que aquí presentamos no son ideas aisladas, segundas lecturas, rebuscadas interpretaciones o inferencias a una borra documental desechada por los especialistas en trance de historiadores. Son simplemente novedades, algunas de calado, que se desprenden del examen al mejor material y que ciertamente sorprenderán a quienes han sido sensibilizados

1 Villalobos, Sergio: "Sugerencias para un enfoque del siglo XIX", Colección Estudios Cieplan, 12, Santiago, 1984, pág. 27.

2 Blancpain, Jean-Pierre: Francia y los franceses en Chile, Santiago, 1987, pág. 190. 
ad nauseam por una historia muy parcial. Aquí abundaremos sobre "la otra inmigración", hasta ahora invisible, compuesta por los proletarios, aventureros, desertores y deudores; y éste es apenas un punto de partida que pretende rectificar errores, llenar vacíos y adelantar nuevos puntos de vista que ciertamente colisionarán con la literatura de "divulgación”. Es lamentable que tantos apurados e interesados juicios, aceptados a fardo cerrado, no hayan sido sometidos a revisión posterior. Es momento de comenzar. ¿Cómo es posible aceptar tantos dislates y repetirlos?

María Rosaria Stabili, muy citada, sin ocupar un papel de información archivística, ha simplificado todo al afirmar, siguiendo a Gonzalo Vial, que "el intercambio comercial, el tráfico naval y la explotación del salitre hicieron llegar a los ingleses; la construcción de las obras públicas y la explotación del cobre a los norteamericanos; la organización de las estructuras educativas superiores y de las estructuras militares a los alemanes. Los franceses arribaron como técnicos agrícolas (especialmente viticultores y enólogos), artistas, arquitectos, paisajistas y comerciantes de productos de lujo para la oligarquía; los italianos arriban para organizar las instituciones culturales-artísticas como el Teatro municipal y la Academia de Bellas Artes, como profesores de la Universidad, pero sobre todo -llamados a Chile por parientes o amigos ya establecidos - controlaban junto a los españoles el pequeño comercio, mientras la venta ambulante estaba bajo el control de los árabes". ${ }^{3}$

\section{Los proletarios-aventureros plurinacionales}

Muchos autores que han orillado el tema de la inmigración extranjera en Chile han pontificado — sin trabajo exhaustivo en archivos - que los flujos europeos fueron, en su gran mayoría, comerciantes, empresarios o empleados prominentes que desarrollaron una gran movilidad ascendente demostrando cualidades de liderazgo y de organización superior. Otros, en sagas apologéticas y sin ningún escrúpulo documental, han "hidalguizado" de un plumazo a una corriente que, plurinacionalmente hablando, estuvo conformada fundamentalmente por elementos de origen proletario. Las "muestras" en que intentan probar lo contrario son tan cortas, que no resisten un análisis serio.

3 Stabili, María Rosaria: "Las políticas inmigratorias de los gobiernos chilenos desde la segunda mitad del siglo pasado hasta la década de 1920", Revista Estudios Migratorios Latinoamericanos, 2, Buenos Aires, 1986, pág. 183. 
Alejándonos de una literatura que está marcada por silencios, lugares comunes, errores de bulto, groseras generalizaciones y alambicadas teorías, los mejores papeles revelan que ya en 1820 , y a pesar de expresas prohibiciones, los extranjeros avecindados en Santiago se ocupaban de abrir tiendas de menudeo; ${ }^{4}$ que María Graham, al visitar la capital en 1822 constató, con cortas excepciones, que los ingleses allí avecindados eran "muy vulgares"; que una representación agitada al gobierno en 1823, rubricada por más de veinte firmas, certificaba "que ningún extranjero podía mantenerse en Chile por menos de $\$ 80$ mensuales"; 6 que en 1827 el inspector general del Comercio Francés acreditado en Chile, al denunciar el arribo del desecho de la población europea a las playas nacionales, argumentaba que si no se extremaban medidas se acumularía en "Santiago un enjambre de gentes sin hogar ni oficios y que prontamente se darían a conocer por sus excesos y acaso sus crímenes"; $;$ que en el marco de los disturbios verificados durante la revolución de 1829 algunos de los súbditos franceses que solicitaron reparaciones "eran prácticamente indigentes"; $;$ que en 1830 algunos de los extranjeros asilados carentes "de toda ocupación con que pudieran ganar el sustento y en ese estado de vagos en que se hallan..." fueron expulsados por violar la neutralidad durante los sucesos del veintinueve;" que en 1831 los tripulantes desembarcados de la corbeta de SMB "Clio", estacionada de Talcahuano, se hallaban casi desnudos y totalmente desamparados, siendo auxiliados en su indigencia por el cónsul británico. ${ }^{10}$ Igualmente, hacia 1841 los "artesanos" extranjeros establecidos en Santiago — poco más de ochenta - se ganaban el pan de cada día en las populares actividades de

4 J. Alcalde y José Villareal al Director Supremo. Santiago, 12 de enero de 1820, en Gazeta Ministerial, número 27. Santiago,1820. Algunos de los nombres de los tenderos extranjeros pueden verse en Carlos Stuardo Ortíz y Juan Eyzaguirre Escobar: Santiago. Contribuyentes, autoridades, funcionarios, agentes diplomáticos y consulares, 1817-1819, Santiago, 1952, págs. 1 y ss.

5 Graham, María: Diario de mi residencia en Chile. Reedición, Santiago, 1988, pág. 152.

6 Archivo Nacional, Fondo Varios (en adelante AN, FV), vol. 331, pza. 88. Valparaíso o Santiago, 20 de junio de 1823. Aparecen, entre otras, las firmas de Moore, Walker, Delegal, Duncan, Stuart, Jullman, Parker, Clarck, Krudall, Widder, Hill, Blest, Burdon y Michael.

7 Archivo Nacional, Fondo Ministerio de Relaciones Exteriores (en adelante AN, FMRREE), vol 7. L. de la Forrest al ministro de Relaciones Exteriores. Santiago, 26 de abril de 1827. Es importante señalar que por ese entonces se aplicó la política de empadronar a los extranjeros residentes en la capital.

8 Lorenzo, Santiago: "Portales y la política internacional", en Bernardino Bravo Lira (compilador): Portales. El hombre y su obra. La consolidación del gobierno civil. Santiago, 1989, pág. 288.

9 Archivo Nacional, Fondo Intendencia de Valparaíso (en adelante AN, FIV), vol. 8. Diego Portales al gobernador de Valparaíso. Santiago, 7 de junio de 1830.

10 Archivo Nacional, Fondo Intendencia de Concepción (en adelante AN, FICO), vol. 108. Información de H. W. Rawn y F. J. Onslow. Concepción, 6 de junio de 1831. 
tenderos, pulperos, bodegoneros, peluqueros y modistas, ${ }^{11}$ que si todos los foráneos eran tan prominentes, cuestión majaderamente reiterada, ¿por qué "capitalistas" como Roberto Bugger, afianzado por Andrés Blest y Eduardo Crosft, o Francisco Álvarez, entre otros, tomaban préstamos de la Caja del Gremio de Jornaleros y Lancheros de Valparaíso por cifras que englobaban, para 1841 y 1849 , la importante suma de $\$ 11.500 ;{ }^{12}$ que en 1844 contingentes británicos provenientes de New South Wales, "muy pobres y desarropados", llevaban una vida llena de privaciones en Valparaíso, y que una sociedad de damas se preocupaba de proporcionarles vestimenta a las mujeres y niños; ${ }^{13}$ que en 1844, en los departamentos de Ancud, Calbuco, Carelmapu, Dalcahue y Castro, los extranjeros que pagaban patente lo hacían fundamentalmente por pulperías y otros despachos por menor; ${ }^{14}$ que si todos eran "ricos", como afirman varios ¿por qué en 1845 los setenta y cinco deudores del comerciante porteño Juan Alonso eran predominantemente franceses, alemanes, británicos y norteamericanos, y sus oficios, apenas, los de marineros, carpinteros, capitanes, sobrecargos, panaderos y

11 Archivo Nacional, Fondo Claudio Gay (en adelante AN, FCCY), vol. 19 y Archivo Nacional, Fondo Ministerio de Interior (en adelante AN, FMI), solicitudes particulares.

12 Archivo Nacional, Fondo Notarial de Valparaíso (en adelante AN, FNV), vol. 58. Escritura de obligación de Roberto Bugger. Valparaíso, 6 de mayo de 1841; Ibídem, vol. 83. Escritura de Francisco Álvarez e hijo. Valparaíso, 14 de julio de 1849.

13 Minna Reclam de Claude a Marie Reclain. Valparaíso, 13 de septiembre de 1844, en Schwarsenberg, Georg (editor): Aus Granny's Nachlab. Sonderabdruch der Gechichlichen Monatshefte des Deustsch-Chilienishen Bundes, 1933, pág. 82. Debemos esta referencia a la profesora Elizabeth Von Loe. Es casi seguro que estos contingentes desheredados de todo fueron parte de los más de 300 que arribaron a Valparaíso en 1843, huyendo de un cataclismo que afectó a Nueva Holanda. Precisamente para ellos se volvió a mover el antiguo proyecto de colonización de los baldíos del sur, lo que a la postre se materializaría en 1845. Curiosamente, para casi todos los autores, repitiendo errores, la ley del cuarenta y cinco fue dictada para dar inicio a la inmigración de contingentes teutones. Nosotros hemos visto: Oficio del presidente de la República que propone un proyecto de Ley que le autorice para colonizar los territorios del sur. Cámara de Diputados, Sesión del 17 de julio de 1844, en Sesiones de los Cuerpos Legislativos de la República, tomo XXXIV, págs. 170 y ss. Un editorial de El Agricultor, núm. 40 (Santiago, diciembre de 1843), aplaude el arribo de agricultores y artesanos de Nueva Holanda. Algunos de estos contingentes se trasladaron hacia la provincia de Concepción convencidos de que el Gobierno les concedería terrenos y auxilios; AN, FIV, vol. 47. J. Prieto al ministro de Interior. Valparaíso, 5 de febrero de 1844. Posteriormente, 29 de ellos, incluidas mujeres y niños, catalogados como "labradores de campo" se reembarcaron en Valparaíso hacia Norte América. AN, FICO, vol. 256, Miguel Bayons al intendente de Concepción. Talcahuano, 5 de diciembre de 1844 .

14 Archivo Nacional, Fondo Intendencia de Chiloé (en adelante AN, FICH), vol. 19. Informe del administrador de Ramos Estancados, José Sánchez. Ancud, 26 de junio de 1844. Entre 1844 y 1854, en la Chimba, Juan Godoy y otros puntos del norte, apellidos como Probost, Iribaron, Mermur, Duncan o Lafosse aparecen vinculados al remate de chinganas y canchas de palitroque. Archivo Nacional, Fondo Intendencia de Atacama (en adelante AN, FIA), vol. 53. Registro de cafés, fondas y chinganas. 
fonderos?:15 que antes de 1850, un baldón para los que aseguran que casi todos llegaban como comerciantes o contratados por firmas extranjeras, la vía de ingreso más importante de ingleses, norteamericanos y franceses fue la deserción, y esos aventureros-proletarios difícilmente pudieron ingresar capitales o maquinarias entre sus improvisados bártulos: ${ }^{16}$ que un número nada despreciable de colonos alemanes eran peones o labradores y que sus mujeres e hijas trabajaron en un comienzo como domésticas de familias chilenas en el sur; ${ }^{17}$ que Vicente Pérez Rosales tachó de "viciosos e inútiles" a algunos de los teutones que colonizaban Llanquihue $;^{18}$ que entre 1830 y 1870 el Estado accedió a las "súplicas" de muchísimos extranjeros que, entre otras cosas, pedían educación gratuita para sus hijos $;{ }^{19}$ que entre 1849 y 1852, en las partidas de "peones para todo servicio" contratados para trabajar en faenas auríferas en California, también figuraban los Daroch, Chebantt, Reed, Alan, Nagel, Wolman, Maffet, Felson, Wilson, Smith, Swett y muchos otros patronímicos extranjeros; $;{ }^{20}$ que entre enero y marzo de 1855, más de cien franceses, ingleses, alemanes, españoles, italianos y norteamericanos fueron atendidos en el hospital de caridad de Valparaíso; ${ }^{21}$ que en los años de 1856, 1857 y 1858 decenas de extranjeros afrontaban "arraigo", por juicios civiles ventilados en el Tribunal del Consulado de Valparaíso; ${ }^{22}$ que en el marco de la escandalosa deserción de marinería norteamericana en Valparaíso y Talcahuano, un comisionado

15 Archivo Nacional, Fondo Judicial de Valparaíso (en adelante AN, FJV), legajo 12, pza. 11. Expediente del Concurso de embargo formado a los bienes de Juan Alonso (1845). Las deudas involucraban \$3. 085, probablemente por ventas "al fiado".

16 En un trabajo histórico hemos individualizado más de 2. 200 individuos que defeccionaron en Valparaíso, Caldera, Constitución, Talcahuano y Chiloé; cifras que son más amplias puesto que en los informes de los attachez foráneos no figuran los que se fugaban luego de que se visaban las nóminas y se despachaban las naves. El problema también se presentó en los años sesenta, setenta y ochenta, aunque palideciendo ostensiblemente; pero comprendió en esos años también a italianos y alemanes. (Véase apartado siguiente). Tratamos exhaustivamente ese tema, incluyendo las acusaciones, descargos, políticas y doctrina consular, en nuestro trabajo "La marinería desertora: un ramal olvidado de la inmigración extranjera en Chile, 1818-1888", en Boletín de la Academia de Historia Naval y Marítima de Chile, 2 (en prensa).

17 Extracto de nota de Vicente Pérez Rosales al ministro de Interior, reproducido en El Araucano. Santiago, 25 de marzo de 1851; Memoria del ministro de Interior, 1858, (en adelante MMI), pág. 282, Oficio de Gaspar del Río al ministro del Interior. Santiago, 15 de junio de 1858; MMI, 1859, pág. 257.

18 MMI, 1853, pág. 247. Vicente Pérez Rosales al ministro de Interior. Puerto Montt, 18 de febrero de 1853 .

19 AN, FMI, volúmenes rotulados solicitudes particulares.

20 AN, FNV, volúmenes varios.

21 El Mercurio. Valparaíso, 28 de marzo de 1855.

22 Información general en AN, FIV, vol. 101. 
especial de la Marina de ese país reconocía en 1860 la posibilidad, y así ocurriría, de que se produjesen disturbios, tumultos y "complicaciones internacionales por el alto número de marineros ociosos, depravados, irresponsables, y generalmente ebrios, en una comunidad, satisfaciendo inclinaciones viciosas y pasiones desenfrenadas", ${ }^{23}$ que entre 1861 y 1870 el número de reos de nacionalidad extranjera llegó en todo el país a 1.041, de los cuales más de la mitad eran ingleses, alemanes, italianos, franceses, norteamericanos y españoles, y cuya incidencia porcentual resulta importantísima si al total de las colonias le descontamos los naturales de los países circunvecinos; $;^{24}$ que en 1858 grupos de alemanes pobres actuaban como "musiqueros" en lugares públicos de Valparaíso; ${ }^{25}$ que entre 1861 y 1883 muchos de los ingleses establecidos en Copiapó mal podían ser catalogados como empresarios-capitalistas puesto que desarrollaban mayoritariamente los duros oficios de barreteros y apires ${ }^{26}$ que en 1860 , en el principal punto, más de un tercio de los establecimientos pertenecientes a extranjeros afectos a la contribución de patente, correspondía a bodegones, baratillos, casas de posta, fondas, pulperías y tiendas de menudeo, cuestión que echa por tierra las altisonantes declaraciones de varios de que sólo la canalla chilena se ocupaba del "comercio sucio". ${ }^{27}$

23 AN, FMRREE, vol. 108. Informe de Willis Bayley. Valparaíso, 19 de diciembre de 1860. Noticias sobre desórdenes cometidos por tripulaciones norteamericanas e inglesas en Coquimbo, Valparaíso, Concepción y Talcahuano entre 1853 y 1867, en Archivo Nacional, Fondo Intendencia de Coquimbo (en adelante AN, FICQ), vol. 517; AN, FMRREE, vol. 69; AN, FIV, vol. 115; AN, FMRREE, vol. 108; AN, FICO, vol. 368. Un ejemplo: en 1862, un marinero inglés que maltrataba a una mujer en una calle porteña fue apresado por un piquete de policías; posteriormente serían atacados por unos cincuenta tripulantes de esa nacionalidad armados con navajas y salvavidas. En la trifulca, que terminó con varios heridos, terciarían también paisanos chilenos y marineros norteamericanos que ayudaron a las fuerzas de orden. AN, FIV, vol. 159. F. Valdivieso al intendente de Valparaíso. Valparaíso, 11 de julio de 1862 .

24 Garrido, Eugenia: Acontecer infausto y mentalidad. El crimen en Valparaíso. Tesis para optar al Grado de Magister en Historia. Universidad Católica de Valparaíso, Valparaíso, 1991, pág. 233. Es importante consignar que centenares de extranjeros condenados por homicidio, robos y heridas fueron indultados por el presidente de la República y el Consejo de Estado. Hemos visto: Archivo Nacional, Fondo Actas del Consejo de Estado (en adelante AN, FACE); AN, FIV; AN, FMRREE; Ministerio de Relaciones Exteriores, Archivo General Histórico (en adelante MRREE, AGH), volúmenes diversos. Hacia 1937-1938 todavía era preocupante la estadística relacionada con delitos cometidos por extranjeros; de hecho, en esos años ingresaron a presidios, cárceles y casas de corrección 114 alemanes, 847 españoles, 418 italianos, 176 turcos, 131 árabes, 33 ingleses, etc. Dirección General de Estadísticas: Política, administración, justicia y educación; 1937, págs. 74-75; 1938, págs. 72-73.

25 "Nuevos huéspedes en Valparaíso", en El Mercurio. Valparaíso, 27 de octubre de 1858.

26 AN, FIA, vol. 247, Registro del panteón de disidentes de Copiapó.

27 Archivo Nacional, Fondo Ministerio de Hacienda (en adelante AN, FMH), vol. 412, Matrícula de las casas de comercio y demás establecimientos sujetos por la ley al pago de la contribución de patentes, formada en Valparaíso. Agosto de 1860. 
En 1870, lamentando no contar con información para otros períodos, en el hospital de caridad de Valparaíso fueron asistidos 709 extranjeros, entre los que se contaban 181 ingleses, 92 franceses, 87 norteamericanos, 151 alemanes, 23 irlandeses, 20 italianos, 21 portugueses, 18 holandeses y 16 belgas, entre otros; ${ }^{28}$ que en 1876 muchos europeos mendigaban por las calles de Santiago; ${ }^{29}$ que en 1880, nuevamente en la capital, grupos de británicos limosneaban y lavaban sus harapos en lugares públicos a vista y paciencia de todos,$^{30}$ lo que echa por tierra las afirmaciones de que todos los extranjeros mudaron rápidamente de posición económica y social, pues más de un tercio de los europeos con profesión censados en 1885 y 1895 desempeñaban los oficios de afiladores, albañiles, bordadores, caballerizos, carpinteros, carretoneros, cocineros, costureras, enyesadores, estucadores, fleteros, lancheros, gañanes, tejedoras, hojalateros, jardineros, fondistas, jornaleros, labradores, lavanderas, marineros, modistas, paragueros, sirvientes, vendedores ambulantes y otras denominaciones "bajas"; $; 1$ que, al caer de los años ochenta, el número de extranjeros buscando trabajo en diversos lugares del país se ensanchó dramáticamente, y al comenzar los noventa aumentó peligrosamente la presencia de desesperados, reducidos a la mendicidad al faltarles pan y trabajo, ${ }^{32}$ que por ese entonces nuestras autoridades ordenaron "suprimir" en absoluto la contratación de italianos al constatarse que unos mil prolongaban indefinidamente su permanencia en las hospederías habilitadas donde se les procuraba de comida y habitación gratuita; ${ }^{33}$ que en 1885 la Sociedad Española de Beneficencia ocupábase de sepultar a los paisanos que fallecían en completa indigencia; ${ }^{34}$ que

28 El Mercurio. Valparaíso, 31 de diciembre de 1870.

29 La Industria Chilena. Santiago, 2 de octubre de 1876.

30 El Independiente. Santiago, 28 de octubre de 1880.

31 Harris Bucher, Gilberto: Participación de los extranjeros con profesión en las estructuras productivas nacionales, a la luz de los Censos de Población de 1885 y 1895 . Ponencia presentada en las II Jornadas Sociales de Chile y América. Universidad de Playa Ancha, Valparaíso, 1992.

32 Para todo: AN, FMRREE, vol. 439. Carlos Colmann al director de la Oficina de Inmigración Libre. Valparaíso, 2 de agosto de 1889; Ibídem, Pasajes libres extendidos por la Oficina de Inmigración Libre. Agosto y septiembre de 1889; Ibídem, Urbano Prieto al M. de Colonización. Santiago, 22 de julio de 1891, indicando claramente la existencia de muchos reducidos a la mendicidad. En 1889 un catedrático de la Universidad de Chile señalaba que además de los muchos a los que les costaba aclimatarse en el país, también llegaban "otros que son de la opinión de que se puede vivir en el país sin trabajar... Chile [también] tiene tanto interés en evitar que aumente de tal modo su proletariado”. Ibídem, vol. 211. Juan Shulze al ministro de Relaciones Exteriores. Santiago, 28 de junio de 1889.

33 MRREE, AGH, vol. 155. J. Mackenna al agente de Colonización de Chile en París. Santiago, 15 de julio de 1890 .

34 Universidad de Chile, Museo Nacional de Medicina, caja 3 (1893-1899). A. Polanco al tesorero de los establecimientos de beneficiencia de Santiago. Santiago, 19 de octubre de 1895. 
en 1889 y 1890 , de acuerdo con un medio informativo, los emigrados subvencionados por el Estado eran "harapientos que desde que llegan no tratan de buscar trabajo, ni de establecer una industria, sino que se van directamente a la Casa que sirve de agencia de transporte para la República Argentina"; ${ }^{35}$ en fin, hacia 1907, centenares de italianos, españoles, franceses y alemanes, muchos enfermos y reducidos a una gran estrechez, asediaban diariamente nuestro consulado en Panamá, logrando finalmente ser contratados y trasladados hacia Chile. ${ }^{36}$

Por todo lo señalado hasta aquí, nadie podría negar que resultan débiles, insostenibles y fuera de lugar las argumentaciones, siempre al voleo, de que los "europeos avecindados en el país no engrosaron la masa proletaria, sino que mayoritariamente ascendieron a posiciones empresariales". ${ }^{37}$ ¿Intuiciones, generalizaciones o pirotecnia? Blancpain fue más allá al afirmar, rimbombantemente, que los franceses, en un contexto temporal amplio, "contribuyeron a transformar la vida cotidiana de los chilenos, cuyos gustos, aspiraciones y consiguientemente, modo de vida, gracias a estos emigrados, adquirieron más urbanidad, se hicieron más europeos". ${ }^{38}$

\section{El azote de la deserción norteamericana y europea}

Del examen a un cáustico, pero importante número de informes, memoriales, protestas, requisitorias y especialmente reclamos de los cónsules extranjeros acreditados en Chile, puede colegirse que la deserción sistemática de marinería foránea en Coquimbo, Valparaíso, Talcahuano, Coronel y Ancud llegó a ser una "enfermedad endémica", entre los años veinte hasta clarear los ochenta. Las cifras involucradas, poco más de dos mil, de acuerdo a nuestros precisos cómputos — provisionales todavía

35 El Mercurio. Valparaíso, 10 de febrero de 1890, reproduciendo noticias del Eco de Los Andes. Para un agudo observador como Ramón Barros Luco, los extranjeros que arribaban a nuestras costas encontrábanse "destituidos de todo recurso... en circunstancias extremadamente aflictivas". Archivo Nacional, Fondo Ministerio de Industria y Obras Públicas (en adelante AN, FMIOP), vol. 186. Barros Luco al ministro de Industria y Obras Públicas. Santiago, 25 de noviembre de 1887.

36 AN, FMRREE, vol. 1242. Jerónimo Ossa al ministro de Relaciones Exteriores. Panamá, 23 de febrero, 11 de abril y papeles varios correspondientes a 1907.

37 Eso señala Mazzei de Grazia, Leonardo: "Inmigración y mutualismo: la Sociedad Italiana Mutuo Soccorso Concordia de Concepción", Formas de sociabilidad en Chile. 1840-1940. Santiago, 1992, pág. 210.

38 Blancpain: Francia y los franceses..., pág. 274. Resulta difícil aceptar que cientos de desertores galos, como veremos más adelante, pudieran haber contribuido a transformar la vida cotidiana de los nuestros. 
mientras no prosiga nuestra pesquisa documental; probablemente deberán pulsar al doble o el triple si consideramos que en los informes de los attachez no figuran los que se fugaban luego de que se visaban las nóminas y se despachaban las naves-, abarcan fundamentalmente a tripulaciones británicas, norteamericanas y francesas, y muy rezagadas numéricamente, las italianas y alemanas. ${ }^{39}$

En un contexto amplio, nuestras referencias, aunque sean forzosamente incompletas y presenten lagunas de calado - especialmente para los años sesenta - vienen a poner en tela de juicio el argumento, tan manido, de que los flujos alógenos desarrollaron una gran movilidad ascendente demostrando cualidades de liderazgo y de organización superior, feble "apreciación" que en otro lugar hemos revisado. ${ }^{40}$ En las líneas que siguen examinaremos ciertos aspectos sobre uno de los ramales, o vía de ingreso no directa, más importante de la inmigración extranjera; el que dice relación con los desertores, o lo que es lo mismo, sobre los proletarios y aventureros. Sobre esto mismo, más de alguno podría contrargumentar que probablemente estos contingentes fueron "aves de paso" que en caso alguno sentaron sus reales en el país. Mas, hay evidencia documental que abona ampliamente la tesis de que se habrían radicado en número importante en nuestras latitudes. Por ejemplo, en los relevamientos de población de 1885 y 1895 , y antes también, la marinería europea y norteamericana muestra importantes guarismos — más de cinco mil almas, en ambos casos-, cifras que deben ser más amplias puesto que no engloban a los registrados en los censos de bahía. Asimismo, para los años sesenta y setenta, el segmento marinería es particularmente expresivo en relación a las defunciones consignadas en las actas de los cementerios de disidentes de Copiapó, Caldera y Valparaíso. Más aún, en toda la centuria la presencia extranjera en la marina mercante chilena — y de capitán a paje — fue a todas luces importantísima. También, en contra de la tendencia endogámica "total", que pregonan los especialistas en inmigración, se ha calculado que en las actas de

39 Documentación: AN, FMRREE, vols. 7, 20, 33, 39, 46, 51, 53, 60, 66, 69, 70, 108, 180; AN, FICO, vols. 109, 158, 159, 176, 198, 240, 242, 263, 337, 368, 409, 670 y 679; Archivo Nacional, Fondo Ministerio de Marina (en adelante AN, FMM), vols. 12, 61, 85, 86, 256 y 285; AN, FICQ, vols. 27, 373 y 31; AN, FIV, vols. 31, 61, 82, 115, 153, 159, 296, 343, 386, 442 y 548; MRREE, AGH, vols. 2, 5, 7, 13 y 24; Archivo Nacional, Fondo Gobernación de Constitución (en adelante AN, FGCC), vol. 2; AN, FIA, vols. 15, 77 y 347; AN, FICH, vols. 7, 9, 18 y 85.

40 Harris Bucher, Gilberto: "Inmigración y emigración en Chile durante el siglo XIX: revisión de conceptos para nuevas interpretaciones", en Actas de las V Jornadas de Historia de Chile. Universidad de Playa Ancha, reproducidas ahora en Revista Notas Históricas y Geográficas, 4. Valparaíso, 1994, págs. 241-267. 
informaciones matrimoniales de las parroquias porteñas de La Matriz, Doce Apóstoles y Espíritu Santo en la brecha 1845-1885, aproximadamente un $10 \%$ de los novios eran extranjeros que casaban con chilenas, y en lo tocante a La Matriz, que hemos revisado, un alto porcentaje corresponde a marinería de patronímico británico o norteamericano. También hemos calculado en un par de miles, para el período 1876-1880 — probablemente muchos más, por no tener información para todo el país-, las tripulaciones foráneas que oficializaron su enganche en las Oficinas de marineros de Caldera, Lota, Coronel, Tomé y Talcahuano..$^{41} \mathrm{Y}$ si de cifras esclarecedoras se trata, es importante consignar que la oficina general de enganche de marineros de Valparaíso proporcionó en 1868 y 1869 más de tres mil libretas de enrolamiento a extranjeros, cifras que son más amplias puesto que las casas de agencias y los consulados siempre embarcaban a muchos más. Si considerásemos que en esos años por lo menos fueron enrolados unos seis mil extranjeros, cifra todavía bajista, éstos representarían el 27,2\% del total de los forasteros residentes en Chile considerando el censo de población de 1865; ese porcentaje es tremendamente importante puesto que de los 21.982 extranjeros registrados sólo 12.613 eran europeos o norteamericanos. ${ }^{42}$

Por otra parte, a la hora de indicar problemas importantes y de larga duración, hay que señalar que la defección de las tripulaciones extran-

41 Harris Bucher: Participación de los extranjeros...; del mismo: Emigración y políticas gubernamentales en Chile durante el siglo diecinueve. Tesis para optar al Grado de Magister en Historia. Instituto de Historia. Universidad Católica de Valparaíso, Valparaíso, 1993; Actas y Registros de defunciones de los cementerios de disidentes de Copiapó, Caldera y Valparaíso; Salinas, René: "Nupcialidad, familia y funcionamiento del mercado matrimonial en Valparaíso durante el siglo XIX", en Valparaíso. 1536-1986. Valparaíso, 1993; Actas matrimoniales de la Iglesia de La Matriz de Valparaíso; Informes de gobernadores marítimos y papeles de las Oficinas de Enganche de marineros de Caldera, Lota, Coronel y Talcahuano; Memorias del ministro de Marina. Anotemos también que la desnacionalización de las tripulaciones de la marina comercial obligó a las autoridades gubernamentales a permitir que la concurrencia extranjera pulsara hasta dos tercios del total de contingentes, medida que fue necesaria reeditarla frecuentemente. AN, FMRREE, vols. 83, 96 y 84, decretos del 7 de mayo de 1855,7 de julio de 1857, 10 de agosto de 1863 y 3 de agosto de 1865 . En verdad, las medidas del ministro Portales en orden a que las tripulaciones fuesen mayoritariamente chilenas fracasaron rotundamente. Francisco Le Dantec, Diego Portales y Valparaíso, en El Mercurio. Valparaíso, 2 de junio de 1974, manifiesta erróneamente que las medidas tuvieron éxito. En 1853 la Marina Mercante Chilena echaba mano de unos 2.200 a 2.700 tripulantes, de los cuales más de la mitad eran forasteros. Memoria del Ministro de Marina (en adelante MMM), 1853, pág. 433 y MMM, 1855, pág. 395. En 1849 el senador J. Bello fue lapidario al manifestar que la marina comercial no era "más que unos palos con bandera chilena", en la que ni siquiera los capitanes eran nacionales. Cámara de Senadores. Sesión del 11 de julio de 1849 .

42 Hemos visto: MMM (1868), pág. 9; MMM (1869), pág. 6; República de Chile, Censo de Población de 1865 . 
jeras causó serios problemas a los capitanes de naves mercantes, de pesca y de guerra, los que ante la imposibilidad de reemplazar las dotaciones con sus paisanos - extraño con tanto fugado residiendo, como se verá- recurrieron a marinería chilena, la que en gran número era finalmente abandonada en puertos lejanos puesto que el enganche no era por el viaje "en redondo". ${ }^{43}$

Si bien es cierto que la documentación permite situar cronológicamente el problema de las defecciones de extranjeros en la brecha autonomista-separatista ${ }^{44}$ parece ser que desde los años veinte las fugas adquieren mayor notoriedad, lo que se desprende tanto de las cifras involucradas como de las múltiples referencias que tocan el problema. Comenzando, mencionemos que en 1824 el capellán del buque inglés "Cambridge" consignaba que muchos de los británicos residentes en Valparaíso eran desertores que luego se ocupaban en actividades relacionadas con las pulperías y el contrabando; ${ }^{45}$ para 1827 sabemos que el inspector general del Comercio Francés acreditado en Chile, al denunciar el arribo a estas costas del desecho de población europea, explicitaba la notoriedad que ya presentaba el fenómeno de la deserción; ${ }^{46}$ el mismo año el comandante del navío de guerra norteamericano "Congreso" solicitaba el concurso de las autoridades chilenas para "recoger" en Santiago, Quillota y Valparaíso a los fugados que se encontraban en esos puntos; ${ }^{47}$ también en 1827, pero ahora tanto en Talcahuano como Valparaíso, verificábase la huída de nueve marineros ingleses y norteamericanos de los balleneros "Diana" y "Marie Fefton". ${ }^{48}$ Más tarde, en 1833, se producían en Valparaíso deserciones de la

43 El problema, y largas referencias documentales, en Harris Bucher: Emigración y políticas... caps. II y III.

44 Academia Chilena de la Historia, Archivo de Don Bernardo O'Higgins (33 vols., completándose. Santiago, 1946-1994), vol. XI. En ese período, excepcionalmente, también se registraron deserciones de extranjeros desde buques de guerra nacionales. Sabemos que en 1818 los responsables de las naves de corso estacionadas en Coquimbo "sedujeron" a un gran número de las dotaciones de la Escuadra, los que practicaron fuga hacia ese punto. AN, FICQ, vol. 11. José Ignacio Zenteno al intendente de Coquimbo. Valparaíso, 3 de septiembre de 1818.

45 "Diario escrito a bordo del buque de su majestad Cambridge, desde enero de 1824, hasta mayo de 1827, por el reverendo H. S. Chaplain" (traducción de Eduardo Hillman), en Revista Chilena de Historia y Geografía, 32, Santiago, 1919, págs. 406-407.

46 AN, FMRREE, vol. 7. L. de Forrest al ministro de Marina. Santiago, 26 de abril de 1827. Antes, en 1820, registrábanse deserciones de balleneros norteamericanos en Talcahuano. AN, FICO, vol. 337. Representación de capitanes al intendente de Concepción. Talcahuano, 7 de octubre de 1820.

47 AN, FMRREE, vol. 20. J. Francisco Zegers al gobernador de Valparaíso. Santiago, 16 de junio de 1827.

48 AN, FICO, vol. 109. J. Benavente al intendente de Concepción. Talcahuano, 11 de mayo de 1827 y reporte de R. Bladley. Talcahuano, 23 de mayo de 1827. 


\section{GILBERTO HARRIS BUCHER}

fragata norteamericana "Falmouth"; ${ }^{49}$ en 1836, desde Copiapó, eran remitidos a Valparaíso algunos desertores españoles de la nave "María Isabel";50 en 1837 los balleneros franceses "Le Gretry", "La Meuse", "Le Ferdinand" y "Le Nazwal", surtos en la bahía de Coquimbo, habían perdido a siete de sus hombres, ${ }^{51}$ y en Serena este problema también afectaba a la fragata norteamericana "Corintha",52 ese mismo año el representante diplomático de Francia acreditado en Talcahuano manifestaba su molestia por las reiteradas fugas de sus paisanos en ese lugar, ${ }^{53}$ y al año siguiente solicitaba la detención de marinería desertora de las naves "Jorge", "Astrolabe", "Carrera de las Indias" y "Alcance"; 54 en 1838 el capitán de Puerto de Copiapó detenía y remitía a Valparaíso a tres desertores ingleses en el bergantín "San Carlos"; 55 también en 1838, el cónsul francés denunciaba la fuga del buque "Jorge" de sus coterráneos Hamel, Padre e hijo, ocultos en Hualqui, lugar en que también se habían refugiado otros dos que habían abandonado el ballenero "Aramis"; 56 en 1839, el buque de guerra "Samarang" perdía a ocho de sus marineros en Valparaíso. ${ }^{57}$

Para los años cuarenta las referencias documentales permiten precisar la defección de veintinueve tripulantes de la fragata de guerra británica "President", cuya aprehensión era encargada a las autoridades de Quillota, Casablanca, San Antonio, Valparaíso, Constitución y Concepción; ${ }^{58}$ en 1841 el cónsul norteamericano destacado en Talcahuano informaba que proseguía la deserción sistemática de sus paisanos, aunque hacía notar que al menos algunos eran finalmente aprehendidos; ${ }^{59}$ en 1840 y 1843 el encar-

49 Joaquín Tocornal al gobernador de Valparaíso. Santiago, 9 de julio de 1833, en Cruchaga Ossa, Alberto: Jurisprudencia de la Cancillería Chilena hasta 1865. Santiago, 1935, pág. 74.

50 AN, FIA, vol. 15. Félix Vallejo al gobernador de Copiapó. Capitanía de Puerto de Copiapó, 3 de marzo de 1836.

51 AN, FMRREE, vol. 39. Reporte de M. Dubautielle, 1837.

52 AN, FICQ, vol. 27. Samuel Haviland a Francisco Irarrázaval. Serena, 10 de enero de 1837.

53 Ibídem, vol. 158. A. Bardelf al intendente de Concepción. Concepción, 28 de abril de 1837; lo mismo en Ibídem, vol. 159.

54 Ibídem, vol. 158. A. Bardelf al intendente de Concepción. Talcahuano, 8 de enero, 31 de mayo, 27 de junio, 12 de julio y 9 de septiembre de 1834 .

55 AN, FIA, vol. 15. Félix Vallejo al gobernador de Copiapó. Copiapó, 14 de febrero de 1838.

56 AN, FICO, vol. 159. A. Bardelf al intendente de Concepción. Concepción, enero de 1838 y 16 de diciembre de 1838 .

57 AN, FMRREE, vol. 46. Reporte de M. Laughon. Valparaíso, 2 de abril de 1839.

58 Ibídem, vol. 33. Roberto Simpson al ministro de Relaciones Exteriores. Valparaíso, 15 de abril de 1841. Ibídem, vol. 51. J. Walpole al ministro de Relaciones Exteriores. Santiago, 12 de abril de 1841. AN, FICH, vol. 9. Circular del ministro de Interior a los intendentes (1841).

59 AN, FICO, vol. 176. P. Délano al intendente de Concepción. Talcahuano, 15 de febrero y 4 de marzo de 1842 . 


\section{LA INMIGRACIÓN EXTRANJERA EN CHILE A REVISIÓN}

gado de los Asuntos Franceses pedía la detención de tres desertores de las fragatas "Le France" y "Gretry"; ${ }^{60}$ en 1845, en Ancud fugábanse en una chalupa 6 tripulantes de la ballenera norteamericana "Balenay"; ${ }^{61}$ en 1846, en Talcahuano, se fugaban marineros del ballenero "La Reunión";62 ese mismo año la Provincia de Chiloé "se hallaba plagada de marineros desertores, especialmente balleneros franceses y norteamericanos";63 en 1847 arribaban a la costa de la subdelegación de Chanquinque, tras fugarse en Talcahuano, siete tripulantes del ballenero norteamericano "Fracat"; ${ }^{64}$ el mismo año desertaban en la jurisdicción marítima de Atacama cuatro ingleses de la barca "Baltazara", llevándose prendas por valor de $\$ 109 ; 65$ en 1849 el attache español informaba de insubordinaciones y fugas de la fragata "Isabel I", fondeada en Valparaíso, ${ }^{66}$ y para la brecha 1840-1860, de acuerdo a precisos informes diplomáticos, las deserciones de la marinería hispana en Valparaíso constituían "un mal endémico";67 en 1849 el comandante de la Estación Naval de Francia en el Pacífico reaccionaba con alarma por las defecciones que se verificaban diariamente; ${ }^{68}$ en enero de ese

60 Ibídem, vol. 198. A. Bardelf al intendente de Concepción. Talcahuano, 30 de enero de 1840 y 27 de diciembre de 1843 .

61 AN, FICH, vol. 18. Circular del intendente de Chiloé a los gobernadores. Ancud, 21 de enero de 1845 . de 1846 .

62 AN, FICO, vol. 337. A. Cross al intendente de Concepción. Concepción, 21 de octubre

63 AN, FMM, vol. 86. R. de Bernales al ministro de Guerra. Ancud, 20 de enero de 1846. Hacia 1843, por consideraciones estrictamente geopolíticas, nuestras autoridades mostraban gran preocupación por la frecuente presencia de balleneros norteamericanos en los archipiélagos de las Guaitecas y de los Chonos, donde los capitanes y marineros habilitaban chozas y ranchos permanentes. Probablemente de aquellos lugares las tripulaciones fugábanse hacia puntos más septentrionales de la provincia. AN, FICH, vol. 9. R. L. Irarrazábal al intendente de Chiloé. Santiago, 23 de diciembre de 1843.

64 Ibídem, vol. 61 J. M. Bascuñan al ministro de Marina. Talca, 9 de febrero de 1847. AN, FGCC, vol. 2. El mismo al gobernador de Constitución. Talca, 20 de febrero de 1847. Un año antes cuatro franceses eran puestos a disposición del cónsul galo, luego de arribar al puerto de Constitución; sospechosamente declaraban haber naufragado de un buque que navegaba hacia el Callao. AN, FMM, vol. 85. Roberto Simpson al cónsul de Francia. Valparaíso, 26 de octubre de 1846.

65 AN, FIA, vol. 77. Hipólito Ovalle al intendente de Atacama. Copiapó, 8 de abril de 1847.

66 MRREE, AGH, vol. 7. Salvador de Tavira a José Joaquín Pérez. Santiago, 28 de diciembre de 1849. En 1853 y 1854, Tavira insistiría al titular de Relaciones Exteriores sobre la conveniencia de que se firmase un tratado chileno-español para normar sobre el problema de las defecciones de marinería. Ibídem. Tavira a Varas. Santiago, 19 de julio de 1853 y 12 de octubre de 1854.

67 Vargas, Juan Eduardo: "Comercio entre España y América durante la era Isabelina: el intercambio con Chile entre 1844 y 1858”, Boletín de la Academia Chilena de Historia, 103, Santiago, 1993, págs. 254 y ss.

68 AN, FIV, vol. 61. L. Levraud al ministro de Relaciones Exteriores. Santiago, 3 de enero de 1849. AN, FMRREE, vol. 60. Comunicación de la Legación General de Francia en Chile. Santiago, 3 de enero de 1849 


\section{GILBERTO HARRIS BUCHER}

año, de 31 reos confinados en la cárcel de Talcahuano, 24 eran marineros extranjeros remitidos por la capitanía de puerto, no faltando los encarcelados a solicitud de los cónsules extranjeros. ${ }^{69}$

Con respecto a los datos de que disponemos para la década de los cincuenta, todo indica que el problema pulsó a cifras más importantes. Por ejemplo, en 1850 las naves galas "Le Roe", "La Henriette", "Le Rochen" y "La Elisa" habían perdido gran parte de sus tripulaciones en Valparaíso, y a la fragata de guerra "L'Poursminot" se le habían fugado ciento cincuenta hombres de una dotación total de trescientos cincuenta; ${ }^{70}$ en ese año en un remitido, publicado en el principal periódico porteño, se sentenciaba que "la deserción es ahora el gravamen más pesado que aflige a la marina mercante extranjera"; ${ }^{71}$ asimismo, también en 1850 , se producía la deserción de la nave "Preble" de Roberto Reed, alias Carlos Farwell, reincidente y acusado de hurto ${ }^{72}$ en 1851 la nave norteamericana "Chester" perdía a seis de sus tripulantes en Coquimbo ${ }^{73}$ en 1853 el representante militar del puerto de Talcahuano informaba de frecuentes fugas de la marinería enganchada en naves de bandera foránea ${ }^{74} \mathrm{y}$, también en ese punto, individuos vinculados a las casas de trato protestaban contra el cónsul norteamericano por las reiteradas deserciones de individuos de esa nacionalidad a los que se le había adelantado el prest de enganche; ${ }^{75}$ el mismo año J. Echel evacuaba alarmantes informes al plenipotenciario norteamericano por las frecuentes fugas de connacionales en los puertos del sur; ${ }^{76}$ también en 1853, desertaban en Valparaíso 5 tripulantes del buque SMB "Portland"; ${ }^{77}$ en

69 Informe de visita judicial practicada a la provincia de Concepción, 1849, en Memoria del Ministro de Justicia, Culto e Instrucción Pública (1850), págs. 160 y 161.

70 AN, FMRREE, vol. 66. C. Cazotte al ministro de Relaciones Exteriores. Santiago, 18 de octubre de 1850. Este diplomático también transmitía continuas quejas de capitanes de naves mercantes y de guerra por las frecuentes deserciones. AN, FIV, vol. 61. Cazzote a Varas. Santiago, 20 de agosto de 1850 .

71 El Mercurio. Valparaíso, 15 de noviembre de 1850 (debo esta referencia al distinguido profesor Santiago Lorenzo Schiaffino).

72 AN, FMRREE, vol. 70. Manuel Blanco Encalada al ministro de Relaciones Exteriores. Valparaíso, 21 de octubre de 1850.

73 AN, FICQ, vol. 27. Nómina de desertores. La Herradura, 11 de marzo de 1851.

74 MRREE, AGH, vol. 13. Rafael Sotomayor al juez de Letras de Concepción. Talcahuano, 18 de junio de 1853. También José Ugarte Zenteno al gobernador Marítimo de Talcahuano. Talcahuano, 20 y 22 de junio de 1853.

75 Ibídem. Ramón Arriagada al gobernador de Concepción. Talcahuano, 16 de junio de 1853.

76 AN, FMRREE, vol. 69. J. Echel al plenipotenciario de Estados Unidos en Chile. Talcahuano (1853).

77 AN, FICO, vol. 409. El vicecónsul de Gran Bretaña al intendente de Concepción. Talcahuano, 5 de noviembre de 1853. 
1854 Varas comunicaba al intendente de Valparaíso su convencimiento de que "el fomento y auxilio de la deserción de marineros extranjeros [causaría] perjuicios al comercio"; $; 8$ en ese año siete tripulantes de la fragata norteamericana "Hibernia" defeccionaban en Ancud; ${ }^{79}$ en 1857 el francés Pedro Garnier, desertor del buque "Mégeré", era reclamado por el cónsul de esa nacionalidad y conducido desde Santiago a Valparaíso; ${ }^{80}$ en 1858 una autoridad naval inglesa solicitaba la aprehensión de tres fugados de la nave de combate "Ganges"; ${ }^{81}$ entre 1857 y 1859, de acuerdo a prolijos cálculos de Willis Bayley, comisionado de la Marina de Estados Unidos, habían desertado en Talcahuano y Valparaíso la friolera cifra de mil doscientos cincuenta y cuatro contingentes de esa nacionalidad ${ }^{82}$ en 1859 también se registraban fugas de marineros sardos ${ }^{83}$ entre abril y diciembre de 1860, cinco naves de bandera americana perdían a ciento cincuenta y ocho de sus efectivos ${ }^{84}$ en diciembre de 1866 diez fugados de la fragata española "Adela" encontrábanse detenidos en la cárcel pública de Valparaíso; ${ }^{85}$ también en 1866, los marineros de la barca británica "Florence Danvers" eran tratados como desertores por las autoridades apostadas en Caldera; ${ }^{86}$ en 1868 se producía en Coronel, la fuga de tres tripulantes de la barca inglesa "Scotish Maid". ${ }^{87}$

Posteriormente, ahora en los años setenta y ochenta, el problema de las pérdidas de efectivos extranjeros nuevamente adquieren notoriedad. Para 1873 sabemos, a partir de informes del comandante de la nave gala "Resolvue", que la deserción de contingentes de las naves de comercio

78 Varas al intendente de Valparaíso. Santiago, 18 de abril de 1854, en Cruchaga: Jurisprudencia... , pág. 348.

79 Ibídem. Varas al intendente de Chiloé. Santiago, 27 de abril de 1854.

80 AN, FIV, vol. 115. Manuel Benavides al intendente de Valparaíso. Valparaíso, 22 de diciembre de 1857.

81 Ibídem. El jefe de las Fuerzas Navales de SMB en el Pacífico al intendente de Valparaíso. Valparaíso, 15 de marzo de 1858.

82 AN, FMRREE, vol. 180. J. Bigley al ministro de Relaciones Exteriores, transmitiendo informes del comisionado especial de Estados Unidos encargado de examinar los diferentes consulados y hospitales de la Costa del Pacífico. Valparaíso, 19 de diciembre de 1860.

83 Aquello se infiere de una nota de Urmeneta al cónsul general de Cerdeña en Valparaíso. Santiago, 1 de julio de 1859, en Cruchaga: Jurisprudencia... , pág. 494.

84 AN, FMRREE, vol. 108. Informe de H. Willis. Valparaíso, 19 de diciembre de 1860.

85 AN, FIV, vol. 153. Manuel Antonio Tocornal al intendente de Valparaíso. Santiago, 11 de diciembre de 1863. de 1866.

86 MRREE, AGH, vol. 24. Taylours Thompson a Álvaro Covarrubias. Santiago, 31 de julio

87 AN, FICO, vol. 240. Francisco del Campo al intendente de Concepción, Coronel, 23 de noviembre de 1868 . 
"Lonrobaya" y "Valentín" impedía que abandonasen puerto; 88 en 1874 el cónsul británico destacado en Valparaíso solicitaba el arresto de marinería desertora de las naves "Cotopaiti", "Lavia", "Lima", "Macedonia", "Maipú" y "Bentthon", ${ }^{89}$ en el mismo puerto, en 1875 y 1876, diversos representantes extranjeros solicitaban la captura de decenas de fugados ingleses y de medio centenar de italianos, franceses, alemanes y norteamericanos; ${ }^{90}$ en 1879 y 1880, también en Valparaíso, defeccionaban en número importante contingentes británicos y algunos italianos, alemanes y franceses; ${ }^{91}$ allí, en 1880, desertaban tripulantes de la corbeta alemana "Viñeta" y de otra embarcación no identificada; ${ }^{92}$ en 1881 los cónsules extranjeros solicitaban la aprehensión de siete franceses, cuarenta y dos ingleses y diez alemanes $;{ }^{93}$ en 1882, en Coquimbo, fugábanse marineros de la corbeta alemana "Moltre";94 por esos años, según las observaciones de Albert Davin, respetable viajero francés, el puerto de Iquique se había convertido en "refugio de los desertores de todas las naciones, atraídos por el cebo de los salarios"; 95 en fin, en 1886, y sólo en el puerto de Valparaíso, los diplomáticos extranjeros solicitaban la aprehensión de veintidós británicos y algunos franceses e italianos. ${ }^{96}$

El cuadro hasta aquí trazado, que esperamos ampliar, ${ }^{97}$ da por tierra con muchos puntos de vista acomodaticios vertidos por quienes han pontificado sobre inmigración olvidando realizar el trabajo previo de hurgar en archivos; los datos colacionados sobre la profusa defección de marinería europea y norteamericana permite afirmar con propiedad que todavía hay mucho de provisional. Asimismo, esta información de primera mano

88 AN, FMM, vol. 285. Ibáñez al ministro de Marina, transmitiendo nota del plenipotenciario de Francia en Chile. Santiago, 26 de marzo de 1873.

89 AN, FIV, vol. 296. J. Somers al intendente de Valparaíso (1874).

90 Ibídem, vols. 296 y 343, papeles varios.

91 Ibídem, vols. 386 y 442, papeles varios.

92 Ibídem, vol. 442. El cónsul del Imperio Germánico al intendente de Valparaíso. Valparaíso, 19 de febrero y 14 de diciembre de 1880.

93 Ibídem, papeles varios.

94 AN, FICQ, vol. 373. El cónsul del Imperio Germánico al intendente de Coquimbo. Valparaíso, 5 de mayo de 1882.

95 Davin, Albert: Chile y Perú en tiempos de la guerra del Pacífico, reedición, Santiago, 1992, pág. 159. En ese puerto, hacia 1906, de acuerdo a informes del cónsul de Chile en Hamburgo, agentes sin escrúpulos explotaban a la marinería. Informe Consular. Hamburgo, 31 de enero de 1907, reproducido en El Diario Oficial. Santiago, 4 de mayo de 1907.

96 AN, FIV, vol. 548, papeles varios.

97 El tema de las defecciones corregido y ampliado considerablemente — cifras, referencias, denuncias, contexto, acusaciones, descargos, políticas y doctrina consular, lo abordamos en nuestro trabajo "La marinería desertora... (en prensa). 
demuestra que es una majadería intelectual seguir insistiendo que en la mayoría de los casos los extranjeros lograron éxito económico y ascenso social. ${ }^{98}$ ¿Desertores integrándose a las elites aristocráticas? ¿Desertores en cadena? ¿Desertores empresarios? Pamplinas.

\section{La condición económico-social de los alemanes establecidos en el sur}

Acerca del origen social de los alemanes establecidos en Llanquihue, y en contra de lo sentenciado por la literatura de "divulgación", hay que señalar que muchos eran obreros, peones y jornaleros "sin pasado", quienes en su gran mayoría fueron subvencionados por el Estado chileno. Las pruebas: de un total de 490 alemanes arribados en 1857, el 86,7\% correspondía a inmigrantes contratados; $; 9$ en 1858 el 86\%, de 215 familias, habían recibido ayuda en pasajes, auxilios diversos y metálico ; ${ }^{100}$ finalmente, hacia 1861 el 87,5\% de los colonos habían sido contratados. ${ }^{101}$ No debe creerse, pese a la liberalísima ayuda estatal, siempre silenciada, que los contingentes mudaron rápidamente de condición; tras haber transcurrido bastantes años luego de la radicación, los oficios principales que desarrollaban, en 1858 y 1859, eran los de carpinteros, zapateros, herreros, sirvientes y comerciantes. ${ }^{102}$

Anotemos también que los teutones radicados en Human hacia 1859, en su inmensa mayoría habían sido auxiliados por las administraciones chilenas, abandonando su país en virtud de una importante y liberal ayuda; ${ }^{103}$ sin embargo, poco tiempo después se debatían en la más completa indi-

98 Últimamente, remedando a especialistas chilenos y extranjeros, Crispi, Paula de Dios: Inmigrar en Chile: estudio de una cadena migratoria hispana, Santiago, 1993, pág. 38.

99 MMI, 1857, pág. 26.

100 Ibídem, 1858, pág. 270.

101 Ibídem, 1861, pág. 41.

102 Ibídem, 1858, pág. 282, y 1859, pág. 89, anexo XIX.

103 AN, FGAR, vol. 61. Papeles varios de Vicente Pérez Rosales a diferentes autoridades, 1859. En 1861, el cónsul de Chile en Hamburgo informaba que 200 de sus paisanos estaban dispuestos a colonizar en Human, siempre y cuando pudiesen gozar "de las mismas gracias concedidas a los primeros colonos", amén de las subvenciones de pasajes. AN, FMI, vol. 78. Lume de Lumie al ministro de Interior. Albana, 28 de febrero de 1861. Curiosamente, a los nacionales que solicitaban hijuelas en ese punto se les impedía acceder a franquicias tales como dinero, pensiones, tablas o bueyes. AN, FMI, vol. 582. Decreto de Gobierno del 8 de abril de 1868. 
gencia. ${ }^{104}$ Es más, en una de las "sagas" de Jean-Pierre Blancpain ${ }^{105}$ se nos pretende hacer creer que todos tenían una holgada situación económica. Nosotros preguntamos ¿Por qué todavía en 1868 los alemanes residentes en Valdivia, que indiscutiblemente tenían mejor situación que los establecidos en los alrededores de la laguna, solicitaban auxilios al gobierno para hacer venir a parientes y amigos? ${ }^{106} \mathrm{Y}$ respecto a otras 32 familias de esa nacionalidad establecidas en Human en 1865 la opinión del intendente de Arauco es muy clara: "pertenecientes a la última clase de la Alemania, los colonos, con cortísimas excepciones, no han podido traer capitales, ni conocimientos notables en ninguna industria u oficio". ${ }^{107}$

Pero hay más. Ya en 1849 M. Fehrmann, agente de algunos emigrados alemanes que se habían establecido en Valdivia, insistía en que la emigración debía ser socorrida y protegida por el gobierno con franquicias especiales; ${ }^{108}$ para los artesanos teutones conducidos por C. Mushgay a la laguna de Llanquihue en 1850 fue necesario disponer de galpones, animales y víveres; ${ }^{109}$ en 1870 eran atendidos gratuitamente en el dispensario, hospital y en sus casas un total de 690 almas, la mayoría colonos del sector del lago y Melipulli; ${ }^{110}$ finalmente, todavía hacia los años noventa las administraciones chilenas se ocupaban de gastos "menudos" relacionados con la apertura de sendas, talajes, hijuelizaciones, construcción de escuelas y pago de fletes, traslados internos y "viáticos". ${ }^{111}$

También hay que señalar que los extranjeros que se radicaron en la región de Llanquihue no sufrieron las contingencias que a muchos deparaba el diario vivir en otras latitudes; asimismo, la ayuda estatal, que cubrió casi todo y por mucho tiempo, sacó a muchísimos de una tristísima situación anterior. Y a pesar de que se insistía, muy emocionalmente, que arribaron burgomaestres, científicos universitarios e industriales, éstos representan un puñado que ya ha sido identificado. Pero ¿y el resto, unos siete mil? Es claro que muchos eran "hombres sin pasado". La colonización de

104 Villarino, Joaquín: Estudios sobre la colonización y emigración europea a Chile, Santiago, 1967, pág. 49.

105 Blancpain, Jean-Pierre: Los alemanes en Chile, 1816-1945, Santiago, 1985.

106 AN, FMI, vol. 536. R. Philippi al ministro de Interior. Santiago, 17 de junio de 1868.

107 MMI, 1865, pág. 187. Informe del intendente de Arauco.

108 AN, FMI, vol. 24. Manuel Blanco Encalada al ministro de Interior, transmitiendo datos sobre el particular. Valparaíso, 21 de noviembre de 1849.

109 AN, FV, vol. 277. Bernardo Philipi al intendente de Chiloé. Hamburgo, 15 de agosto de 1850 .

110 AN, FMI, vol. 599. Felipe del Solar al ministro de Interior. Melipulli, 11 de enero de 1871.

111 AN, FMRREE, vol. 753, papeles varios. 


\section{LA INMIGRACIÓN EXTRANJERA EN CHILE A REVISIÓN}

aquel territorio fue una empresa difícil para los inmigrantes y gravosa para las administraciones chilenas; empero, jamás podría compararse, por ejemplo, con la colonización de Magallanes, periferia donde las lluvias y nieves, barrizales y ciénagas dificultaron, y por mucho tiempo, el normal establecimiento humano.

Para los convencidos que hablan de un "sur alemán", ${ }_{112}$ es importante mencionar que aquéllos jamás sobrepasaron numéricamente a los chilenos residentes; sólo de Chiloé más de diez mil habitantes se trasladaron a Valdivia y Llanquihue. ${ }^{13} \mathrm{Y}$ si nos referimos al esfuerzo desplegado por los chilenos mencionemos que los trabajos de apertura de los caminos de Osorno y Melipulli en 1852, incluso la casa que cobijó a los primeros teutones que arribaron a Llanquihue, fueron obras verificadas gracias al concurso de 680 chilotes procedentes de San Carlos, Calbuco e islas vecinas. ${ }^{114}$

Quienes atacaban las campañas propagandísticas y de reclutamiento del gobierno chileno en Europa solían señalar que en nuestro sur los chilenos recibían a los extranjeros con un crucifijo en una mano y un puñal en la otra, cuestión que en verdad no correspondía a una gratuita calumnia; mas, en Valdivia por ejemplo, hacia 1895 veintisiete europeos cumplían condena en la cárcel por diferentes delitos, contándose entre ellos 7 alemanes, 6 austríacos, 1 belga y 13 italianos; ${ }^{115}$ casi 60 años más tarde, concretamente en 1937 y 1938 entre los centenares de hombres y mujeres ingresados a presidio, cárcel y casa de corrección en Valdivia, figuraban 15 alemanes, 1 árabe, 3 argentinos, 1 austríaco, 13 españoles, 1 italiano y 9 turcos. $^{116}$

Al terminar esta sección es importante recordar que la exigua e "hidalguizada" inmigración alemana que recibió nuestro país fue —ex-

112 Por ejemplo Sánchez-Albornoz, Nicolás: La población de América Latina, Madrid, 1973, pág. 171; Humprheys, R. A.: "Los estados de la América Latina", en Cambridge University Press: Historia del Mundo Moderno. 13 vols. Barcelona, 1980, vol. X, pág. 482. Barros, Mario: Historia diplomática de Chile. Barcelona, 1970, incurre en muchos errores al tocar el tema conectado con la colonización. Por ejemplo, en la página 521 consigna que entre 1850 y 1898 arribaron al país 32.000 europeos, predominantemente alemanes (sic).

113 Villalobos: Sugerencias para..., pág. 27.

114 MMI, 1853, págs. 257 y 258. Vicente Pérez Rosales al ministro de Interior. Puerto Montt, 18 de febrero de 1853.

115 República de Chile, Estadística de las cárceles, 1895, reproducida en Contreras, Juan: Criminalidad y sociedad fronteriza: La Araucania en la segunda mitad del siglo XIX, 1860-1910. Tesis para optar al Grado de Magister en Historia. Universidad Católica de Valparaíso, Valparaíso, 1987, pág. 134.

116 Dirección General de Estadística: Política, administración, justicia y educación, 1937, págs. 74-75; 1938, págs. 72-73. 


\section{GILBERTO HARRIS BUCHER}

ceptuando a un puñado de burgueses que alzó el vuelo por los acontecimientos políticos europeos del cuarenta y ocho- presidida exclusivamente por el estado de necesidad o, lo que es lo mismo, para volverle la espalda al pauperismo. Una fuente, bastante autorizada por lo demás, pintaba en los años sesenta el siguiente cuadro sobre los potenciales migrantes teutones, algunos de los cuales recibiría nuestro país: "se encuentra [señala Jules Duval] familias amontonadas en una sola pieza con un tabique de greda por toda separación. Aquellos que poseen una silleta, una mesa, un lecho común, un tiesto de barro por todo utensilio se creen privilegiadas. Algunos andan desnudos y sin zapatos, aun en invierno. $\mathrm{Mu}-$ chos pobres no viven sino de la papa y de una ficticia que apellidan café, mientras los aficionados beben un aguardiente insoportable, destilado de papas, tan ruinoso para el bolsillo como para la salud. En este estado de abandono, la miseria degenera en una espontánea desmoralización, superior a todo remedio, entre cuyas consecuencias los motines de obreros no es el peor síntoma, porque manifiestan todavía cierto resto de energía". ${ }^{117}$ Hacia los años ochenta todavía debe de haber persistido este estado de cosas si consideramos el revuelo que causaban en algunos estados alemanes las liberalísimas franquicias que nuestras administraciones ofrecían a los que deseaban expatriarse. Una autoridad edilicia de Voigstberg graficaba así la reacción de sus paisanos ante las campañas propagandísticas verificadas por nuestros enganchadores: "habiendo éste [aviso] causado gran expectación se permite el muy respetuoso infraescrito a solicitud de varias partes, a preguntar si él descansa en la verdad, y en este caso qué condiciones pone el gobierno a los emigrantes, o si sólo se trata de un embuste". ${ }^{118}$ Otro, un talabartero, más expresivo por cierto, indicaba: "me siento deseoso de emigrar a la República de V.E. no con la esperanza de llegar a ser un propietario sino con el deseo de vivir con menos penalidades que aquí'. 119

117 Duval, Jules: Histoire de l'emigration Europeenne, Asiatique et Africane au XIX siecle, ses causes, ses caracteres, ses effets, París, 1862, citado por Benjamín Vicuña Mackenna: Bases del informe presentado al Supremo Gobierno sobre la inmigración extranjera por la comisión espacial nombrada con este objeto y redactada por el secretario de ella, Santiago, 1865, pág. 65; el original en Archivo Nacional, Fondo Benjamín Vicuña Mackenna, vol. 42.

118 MRREE, AGH, vol. 54. El gobernador del distrito de Voigstberg-Sajonia al presidente de la República. Voigstberg, 8 de diciembre de 1881.

119 Ibídem. Gustav Krause al presidente de la República. Wriegen, 13 de diciembre de 1831. Otro centenar de pobladores de Berlín, Werdam, Wriegen y Schwerin se expresaron en parecidos términos. 


\section{LA INMIGRACIÓN EXTRANJERA EN CHILE A REVISIÓN}

En la literatura apologética que ha rodeado el tema de la inmigración extranjera rarísima vez se menciona que los teutones huían de la pobreza. Es importante mencionar aquí que el ducado de Baden y algunos municipios subvencionaron, entre 1850 y 1855 , la salida de quienes vivían "de la caridad pública"; ${ }^{120}$ Vicente Pérez Rosales fue clarísimo: "playas a donde los condujo la necesidad" ${ }^{121}$ Incluso más tarde nuestro encargado general de Inmigración en Europa señalaría que si se costease el pasaje de los contingentes alemanes y se les asignase una pequeña ayuda económica se encontrarían "miles de emigrantes para cada vapor, reclutados entre la canalla que tanto abunda en Hamburgo, Bremen y demás puertos". ${ }^{122}$

De todo lo reseñado se desprende claramente que el grueso de los alemanes que ingresaron al país fueron contratados por el Estado, y estaban perfectamente interiorizados de que nuestras administraciones correrían con los gastos que demandaba su traslado, que graciosamente les otorgarían en calidad de préstamo tierras — no precisamente muladares—, ${ }^{123}$ útiles de labranza, animales, semillas, todo lo necesario para levantar una vivienda, y más importante aún, que los auxiliaría en su manutención con un diario en dinero durante un año, amen de importantes franquicias tributarias. ${ }^{124}$ Son precisamente estas prerrogativas, que no quedaron en el papel - como piensan algunos - las que los incentivaron a expatriarse.

120 Villarino: Estudios ..., pág. 71. En 1854, eran devueltos desde Norteamérica al Puerto de Bremen 2. 907 emigrantes, "porque eran demasiado pobres". Vicuña Mackenna: "La inmigración europea con relación a Chile", en Miscelánea. Colección de artículos, discursos, biografías, impresiones de viajes, ensayos, estudios sociales y económicos. 3 vols., Santiago, 1872, t. II, pág. 178.

121 Pérez Rosales, Vicente: La colonia de Llanquihue, Santiago, 1870, pág. 31.

122 AN, FMRREE, vol. 260. Francisco de Borja Echeverría al ministro de Relaciones Exteriores. Burdeos, 16 de octubre de 1883.

123 Destacan la calidad de las tierras los más importantes promotores de la inmigración alemana: Bernardo Philippi al ministro de Interior (1843 o 1844), en AN, FICH, vol. 19; haciendo mención a la laguna de Llanquihue; MMI, 1853, pág. 264; Pérez Rosales: La colonia ... , pág. 13.

124 AN, FV, vol. 277. Carlos Muchgay a Vicente Pérez Rosales. Valdivia, 16 de mayo de 1851. AN, FMRREE, vol. 81. D. Shutte al ministro de Relaciones Exteriores. Hamburgo, 28 de julio de 1853, indicando que presentara en Alemania datos sobre resoluciones, providencias gubernamentales, decretos y leyes relacionadas con la colonización de Valdivia; AN, FMI, vol. 78. El agente de colonización de Chile en Alemania al ministro de Interior. Hamburgo, 25 de agosto de 1861; AN, FMI, vol. 536. R. A. Philippi al ministro de Interior. Santiago, 17 de junio de 1868. Archivo Nacional, Fondo Gobernación de Arauco (en adelante AN, FGAR), vol. 61. A. Ovalle al intendente de Arauco. Santiago, 10 de enero de 1859, referida a liberales franquicias ofrecidas por Vicente Pérez Rosales a los alemanes establecidos en Human; AN, FMRREE, vol. 439. C. M. Calmann a Eduardo Philips, transmitiendo solicitud del encargado de Negocios del Consulado Alemán sobre condiciones y facilidades exigidas por Chile a los colonos que vengan de Alemania. Valparaíso, 19 de marzo de 1889. 


\section{Las deudas de los colonos de Llanquihue}

En cuanto a las deudas de los alemanes establecidos en Llanquihue, tema poco arado por la historiografía, nos ocuparemos aquí del período 1852-1868. ${ }^{125}$ Aunque nos ha sido imposible dar con los originales que contienen todas las obligaciones de los teutones - deudas que fueron extinguidas graciosamente por el Gobierno chileno hacia fines del siglo- podemos adelantar que entre 1852 y 1858 la administración Montt había gastado un total de $\$ 172.862$ en la empresa colonizadora, debiendo los europeos reembolsar a la Tesorería provincial cantidades que para ese entonces montaban \$ 68.017. ${ }^{26}$ Hacia abril de 1859 los montos a devolver ascendían a $\$ 105.350^{127}$ y en mayo de 1862 , al momento de vencer el plazo para pagar una de las quintas partes adeudadas, los extranjeros no pagaron $\$ 19.873$, limitándose la máxima autoridad provincial a reconvenirlos extrajudicialmente. ${ }^{128}$ La ayuda en caso alguno cesó; hacia 1868 había aumentado a \$ $119.923^{129}$ y en 1874 llegaba a $\$ 154.327 . .^{130}$

De la atenta lectura del documento original que contiene las deudas de los alemanes de Llanquihue, y que hemos publicado íntegramente en otro lugar, ${ }^{131}$ puede colegirse que las primeras cien asignaciones a cabezas de familia dieron margen a que un $22 \%$ recibiera todo tipo de ayuda entre uno y doce meses, un $30 \%$ entre trece y veinticuatro meses, un $32 \%$ entre veinticinco y treinta y seis meses, un $12 \%$ entre treinta y siete y cuarenta y ocho meses, un $2 \%$ entre sesenta y uno y setenta y dos meses. En cuanto a las segundas cien asignaciones la tónica fue la siguiente: un $15 \%$ recibió toda clase de auxilios entre uno y doce meses,

125 Información completa en AN, FMI, vol. 582.

126 MMI, 1858, págs. 282 y 283.

127 Ibídem, 1861, pág. 41.

128 AN, FMI, vol. 85. Gaspar del Río al ministro de Interior. Puerto Montt, 15 de mayo de 1862.

129 Ibídem, vol. 582. Razón de las deudas que tienen los colonos de Llanquihue, sacada de los libros que existen en la Aduana y Tesorerías Unidas de la misma provincia. Comprende desde la fundación de la colonia hasta el 31 de marzo de 1868.

130 Mensaje del presidente de la República sobre las cantidades adeudadas por los colonos de Llanquihue, en Cámara de Diputados. Sesión Ordinaria del 8 de julio de 1885.

131 Harris Bucher, Gilberto: "Un documento sobre las deudas de los colonos alemanes de Llanquihue con el Estado de Chile, 1852-1868, con introducción y notas", Revista Notas Históricas y Geográficas, 5. Valparaíso (en prensa). 
un $77 \%$ entre trece y veinticuatro meses, un $4 \%$ entre treinta y siete y cuarenta y ocho meses. En cuanto a las últimas noventa y cinco, el cuadro es el que sigue: un 38,9\% recibió ayuda entre uno y doce meses, un $47,3 \%$ entre trece y veinticuatro meses, un $7,36 \%$ entre veinticinco y treinta y seis meses y un $3,15 \%$ entre treinta y siete y cuarenta y ocho meses. Ahora en relación a los débitos totales de la colonia, señalemos que entre abril de 1852 y julio de 1867 sólo un 2,3\% había abonado porcentajes fluctuantes entre un 6,2\% y un $40 \%$; el resto no había pagado absolutamente nada. Finalmente, del total de \$ 111.923 invertidos desde la fundación de la colonia hasta julio de 1867, sólo se había devuelto un irrelevante $2 \% .132$

Aunque nuestras autoridades tempranamente habían confiado en el servicio regular de la devolución parcializada de las quintas partes adeudadas, ${ }^{133}$ el servicio falló totalmente, como puede deducirse de las fuentes, ya que la gran mayoría de los colonos no habían cancelado absolutamente nada. ${ }^{134} \mathrm{Y}$ es importante consignar que los auxilios sobrepasaron, y en mucho, los doce meses que estipulaban los decretos y reglamentos que vinieron a ampliar la Ley de Tierras de 1845. También se equivocaron los miembros de una comisión encargada de investigar "el estado de fortuna de los colonos deudores", quienes en 1876 llegaron a concluir que en cuatro años podría recuperarse un $64,8 \%$ de los totales devengados. ${ }^{135}$ Finalmente sería presentada a la Cámara de Diputados una moción para condonar las deudas contraídas con el fisco. ${ }^{136}$

132 Blancpain, Jean-Pierre: "La tradición campesina alemana en Chile", Boletín de la Academia Chilena de la Historia, 81, Santiago, 1969, pág. 89, indica acomodaticiamente que la "falta de fondos de la tesorería obligaba a los colonos a depender de sí mismos". Esta afirmación es, cuando menos, risible.

133 MMI, 1846, pág. 427, y 1859, pág. 35. Al respecto Vicente Pérez Rosales pensaba lo siguiente: "El primer año de su llegada es año perdido para su reintegro. El segundo apenas puede contar con qué vivir y no es prudente apurarlo. El tercero ya puede comenzar a hacer sus pagos y continuarlos de año en año por cuartas partes hasta su completa cancelación. “AN, FMI, vol. 85. Indicaciones sobre los deberes del agente en Europa para impulsar la emigración extranjera en Chile (s. a. ).

134 Apenas quince, de doscientos noventa y cinco, habían pagado todo o abonado partes.

135 Cámara de Senadores, Sesión Extraordinaria del 19 de octubre de 1877.

136 Moción del diputado Manuel Balbontín para condonar las deudas contraídas por los colonos de Llanquihue, en Cámara de Diputados, Sesión Extraordinaria del 30 de agosto de 1890. En esa sesión los pareceres de Balbontín, apoyados unánimemente, fueron los siguientes: "A mi juicio el único medio posible, eficaz e inmediato de extinguir una deuda semejante, de origen objetable, de plazo antiquísimo, de un valor primitivo pequeño, de molesta y costosa cobranza y cuya subsistencia es ocasionada a detestables abusos, no puede ser otro que una simple y total condonación". 


\section{GILBERTO HARRIS BUCHER}

Como posdata para todo nos resta rectificar dos erratas notables: a Eduardo Tampe quien, al voleo, señala que a los colonos "nada les fue regalado ni condonado", ${ }^{137}$ y a María Rosaria Stabili, quien afirma, sorprendentemente, que los alemanes "sin disponer de ningún anticipo, solventaron los gastos del viaje y de la primera instalación y a menudo también aquellos relacionados con la adquisición de bienes inmuebles, en forma tal que su radicación no le costó nada al Estado chileno", ${ }^{138}$ cuestiones que son absolutamente falsas.

137 Tampe, Eduardo: "El lago Llanquihue centro de la colonización alemana", en Liga Chileno Alemana: Llanquihue: 1852-1977. Aspectos de una colonización, Santiago, 1977, pág. 92.

138 Stabili: "Las políticas inmigratorias...", pág. 186. Pero ese error no fue suficiente, puesto que plantea que ya desde los primeros años de vida independiente la inmigración no es asistida directamente por el Estado; señala que a Pérez Rosales le encargaron radicar colonos alemanes en Valparaíso y que Chile recibió, entre 1850 y 1897, sólo 3. 528 extranjeros. Para qué continuar... Y lo que llama más nuestra atención es que los especialistas chilenos citan a esta autora como si fuese autoridad sobre el tema. Insistimos, hay que elevar el nivel. 